\title{
Movimento de luta das mulheres nos poemas de Storni: uma proposta de tradução
}

Movimiento de lucha de las mujeres en los poemas de Storni: una propuesta de traducción

\section{Antonella Romina Savia Vidales}

Universidade Federal de Pelotas - UFPEL - Rio Grande do Sul - Brasil

\begin{abstract}
Resumo: Neste artigo, apresentam-se as traduções em português de dois poemas, de Alfonsina Storni, quais sejam: "Bien pudiera ser" e "Van pasando mujeres". A prática tradutória pautou-se nas reflexões acerca da linguagem e do ritmo, propostas por Henri Meschonnic, em seu Poética do traduzir. Conforme propõe tal pensador da tradução, o processo de traduzir não pode furtar-se a relacionar a discussão linguística e literária, considerando o que faz com que um poema produza determinado efeito, através da análise do ritmo. Dessa forma, foi necessário, neste trabalho, observar, durante a prática tradutória, as rimas, os acentos, os ecos prosódicos, ou seja, os efeitos produzidos pelos poemas, a fim de recriá-los em suas respectivas traduções. Por fim, este artigo apresenta ainda reflexões acerca da análise do ritmo dos poemas, bem como das escolhas tradutórias dos quais lançou mão.
\end{abstract}

Palavras-chave: Poética do traduzir. Ritmo. Alfonsina Storni.

Resumen: En este artículo se presentan las traducciones al portugués de dos poemas de Alfonsina Storni, a saber: "Bien pudiera ser" y "Van pasando mujeres". La práctica de la traducción se basó en las reflexiones sobre el lenguaje y el ritmo, propuestas por Henri Meschonnic, en su Poética del traducir. Tal como lo propone el pensador de la traducción, el proceso de traducir no puede evitar relacionar la discusión lingüística y literaria, considerando qué hace que un poema produzca un cierto efecto, a través del análisis del ritmo. Así, fue necesario, en este trabajo, observar, durante la práctica traductora, las rimas, acentuación, ecos prosódicos, es decir, los efectos producidos por los poemas, para recrearlos en sus respectivas traducciones. Finalmente, este artículo presenta aún reflexiones sobre el análisis del ritmo de los poemas, así como sobre las opciones de traducción elegidas.

Palabras-clave: Poética del traducir. Ritmo. Alfonsina Storni. 


\section{Introdução}

Com o intuito de trazer ao debate um teórico que ainda merece mais reflexões no Brasil, Henri Meschonnic, desenvolvemos um trabalho de dissertação de mestrado sobre tradução ${ }^{1}$ que, pautado em sua teorização, não distanciou a discussão entre o linguístico e o literário. A pesquisa propôs, considerando a poética do traduzir, a tradução de seis poemas de Alfonsina Storni.

A poética do traduzir, proposta por Meschonnic, sustenta-se nas reflexões de três estudiosos da linguagem: Wilhelm von Humboldt, Ferdinand de Saussure e Émile Benveniste. Essa proposta busca articular uma concepção de linguagem que, considerando a relação de indissociabilidade entre língua, cultura e sociedade, aponta para a impossibilidade de se erigir fronteiras entre os estudos da linguagem, os estudos literários e os estudos tradutórios. Por isso, a poética surge como uma reflexão de linguagem acerca do processo tradutório. O texto, nessa perspectiva, é tomado como um sistema de discurso a ser traduzido.

Considerando essa reflexão teórica, proposta por Meschonnic em sua poética, este artigo trata-se de um recorte do trabalho de dissertação, acima referido, e propõe-se a apresentar duas, das seis traduções realizadas. Inicialmente desenvolvemos conceitos teóricos relevantes para o trabalho. Em seguida, apresentamos os poemas e as análises, procurando o ritmo de cada poema. Por fim, expomos as traduções e as análises sobre o processo de tradução.

\section{A poética do traduzir}

Meschonnic desenvolve a poética do traduzir pautado no conceito de ritmo. A noção de ritmo considerada pelo teórico tem como base a discussão acerca dessa noção feita por Benveniste ([1966] 2005) no texto "A noção de ritmo na sua expressão linguística". Quando se passa a considerar o ritmo como organização do discurso, observa-se o contínuo na linguagem deixando de olhar o binário do signo. Assim, na perspectiva de Meschonnic ([1999] 2010, p. 62), deixa-se de considerar o signo como binário, que pressupunha apenas o oral e o escrito, e, por meio do ritmo, passa-se a considerar um modelo triplo que pressupõe o falado, o escrito e o oral., sendo por meio da oralidade que observa-se o ritmo do texto escrito.

Partindo das considerações feitas por Benveniste, Meschonnic coloca em debate a noção de oralidade e propõe que o oral está presente também no texto escrito, e não apenas no falado. A oralidade traz para o texto um novo olhar, o efeito de escuta que produz o modo de significar da tradução. E esse modo de significar vai além do sentido corrente das palavras, está na escrita, no que Meschonnic chamou de corpo na linguagem. Esse corpo produz uma oralidade, uma subjetivação que pode ser percebida no texto escrito através do ritmo.

Dessa forma, Meschonnic propõe uma nova forma de conceber a tradução, através da poética do traduzir. Nessa perspectiva, traduzir é partir do princípio de que a linguagem não é apenas língua, mas sim discurso. A poética meschonniquiana considera que as palavras possuem um sentido além, um sentido que é produzido pelo ritmo. Assim, a tradução pauta-se na significância produzida no sistema de discurso. A poética coloca em relação a literatura e linguagem, situando a tradução dentro de uma teoria da sociedade.

Na poética, há um sujeito do poema inscrito no ritmo da linguagem. Dessa forma, as traduções de inspiração meschonniquiana não devem dissociar a forma e o sentido, o som e sentido. Tais traduções devem fazer algo e não somente dizer. Para Meschonnic, o tradutor deve considerar a enunciação, e não o enunciado, colocando-se em uma situação de escuta do texto a traduzir, devendo traduzir a forma e o sentido, o som e sentido conjuntamente.

Cabe relembrar que Meschonnic ([1999] 2010) parte das reflexões acerca da linguagem em Saussure e Benveniste. Assim, a poética concebe o discurso como sistema, levando em conta o valor, o

\footnotetext{
11 Intitulado A escuta da voz feminina nos poemas de Storni: 
funcionamento, o radicalmente arbitrário, na concepção saussuriana, e a noção de discurso, a enunciação como atividade do sujeito, na concepção benvenistiana. Para Meschonnic ([1999] 2010), ao traduzir, deve-se considerar o contínuo do discurso, atentando para o ritmo.

Com a proposta poética do traduzir e a noção de ritmo, o processo tradutório é repensando. A relação com a linguagem vai além da língua, passa pelo discurso. O teórico destaca que o ritmo geralmente é estudado por outras linhas teóricas como a fonética, e quase nunca pela linguística. Ele enfatiza ainda que a literatura, geralmente, observa questões relacionadas à métrica ou às metáforas musicais ao levar em consideração o ritmo, enquanto que poética leva em conta o ritmo como a organização do movimento das palavras, do discurso por um sujeito e do sujeito por um discurso. Assim, a unidade da poética é o texto como um sistema de discurso.

O ritmo proposto por Meschonnic difere do ritmo que tem suas raízes na música, como explica Neumann (2016) em sua tese. Assim "[...] o ritmo na poesia é diferente do ritmo na música, de forma radical, tanto porque ele é aí linguagem, quando porque está na linguagem" (NEUMANN, 2016, p. 99), não sendo possível assim pensar o ritmo como um só para a música, para o poema e para a linguagem.

Com isso, o ritmo no poema, na linguagem deve ser pensado na relação entre a forma e o sentido, o som e o sentido. O ritmo, tal como considerado por Meschonnic, está ligado ao todo do discurso, o que promove uma relação entre o ritmo e o discurso. Assim, Meschonnic parte dos estudos benvenistianos e propõe um ritmo que pensa a particularidade da linguagem, uma poética do ritmo.

A partir da proposta de Meschonnic, deixa-se de pensar o ritmo como medida, e passa-se a pensar o sentido do discurso que não pode ser medido. Neumann (2016) destaca que, ao considerar o poema e analisá-lo a partir do sentido, passamos a analisar os múltiplos ritmos do discurso, tornando-se viáveis múltiplos sentidos. Dessa forma, as análises consideram questões que vão além da métrica que era proposta antes, agora a prosódia e a entonação fazem parte das análises do ritmo. Neumann (2016) acrescenta que "não se pode ler o ritmo, mas é possível escutá-lo naquilo que se lê e no que não se pode ler sem ele" (p. 108). É por meio do ritmo que são produzidos sentidos novos no sistema de discurso a ser traduzido.

Meschonnic apresenta então uma noção de ritmo na qual se estabelece uma hierarquia de análise. O ritmo produz a métrica, o ritmo guia o olhar para o que dever ser priorizado, não sendo mais a métrica e a contagem silábica as norteadoras da análise. O ritmo é subjetividade, marcação do sujeito pelo discurso, é enunciação. Assim, Meschonnic ([1999] 2010) enfatiza que a relação entre o sentido, o ritmo e o sujeito produz o discurso, portanto, não se parte mais da métrica do verso para encontrar e analisar o ritmo, parte-se, agora, do discurso.

A poética do traduzir propõe então uma nova forma de considerarmos a tradução e coloca em evidência a noção de ritmo como norteadora do processo tradutório. Para o teórico, a poética tem como unidade o texto, carregado de historicidade e ritmo. Nessa perspectiva, a forma e o sentido, o som e o sentido são indissociáveis e permitem que o ritmo transforme o escrever e o traduzir.

\section{Análise do ritmo dos poemas de Storni}

Nossas análises observaram o todo do texto, ou seja, consideraram a métrica, a rima, a escansão, os acentos, as repetições sintáticas. Com a poética do traduzir, observa-se o texto e hierarquiza-se as questões de análises, conforme o ritmo vai impondo e, logo, recria-se na outra língua o efeito do texto original. Na proposta da poética do traduzir, deve-se observar a acentuação dos poemas. Dessons (2011 apud NEUMANN, 2016) explica que a acentuação é essencial para a significação do poema. Assim, ele ressalta que há dois tipos de acentuação: o acento principal, essencial para o ritmo da linguagem, e o acento secundário, específico do discurso. Dentro da acentuação principal, Dessons destaca que há o acento sintático (ou de grupo) e o prosódico.

Neumann (2016) explica que o acento sintático em francês recai na última sílaba dos grupos 
sintáticos ${ }^{2}$, porém no português, assim como no espanhol, pode recair sobre a penúltima, última ou antepenúltima sílaba. Por sua vez, o acento prosódico é observado na repetição de fonemas consonânticos em posição de ataque. Esse acento está ligado à paranomásia, ou seja, é a união de palavras na mesma frase com sons similares, porém com sentidos diferentes. Nossas análises foram feitas marcando as sílabas acentuadas e buscando ouvir os acentos, atentando para a voz que perpassa o poema.

Os poemas serão apresentados da seguinte forma: primeiramente os poemas em língua espanhola junto com as análises da métrica, escansão e destaque de sílabas tônicas. Logo, uma breve análise do poema observando as relações entre rimas, acentos sintáticos e prosódicos, repetições sintáticas, pensando no projeto de tradução. Por último, a proposta de tradução e uma análise e registro do percurso tradutório.

O primeiro poema que apresentamos é Bien pudiera ser, publicado por Alfonsina Storni em 1919, no livro Irremediablemente.

Pudiera ser que todo lo que en verso he sentido

no fuera más que aquello que nunca pudo ser,

no fuera más que algo vedado y reprimido de familia en familia, de mujer en mujer.

Dicen que en los solares de mi gente, medido estaba todo aquello que se debía hacer... Dicen que silenciosas las mujeres han sido de mi casa materna... Ah, bien pudiera ser...

A veces a mi madre apuntaron antojos de liberarse, pero, se le subió a los ojos una honda amargura, y en la sombra lloró.

Y todo eso mordiente, vencido, mutilado, todo eso que se hallaba en su alma encerrado,

pienso que sin quererlo lo he libertado yo.

A seguir, apresentamos a escansão do poema usando a métrica espanhola, grafando as sílabas fortes a fim de ouvir os acentos sintáticos do poema.

pu-die-ra-ser-que-to-do-lo-queen-ver-

sohe-sen-ti-do = 14

no-fue-ra-más-quea-que-llo-que-nun-ca-

pu-do-ser $=14$

no-fue-ra-más-queal-go-ve-da-doy-re-pri-

mi-do $=13$

de-fa-mi-liaen-fa-mi-lia-de-mu-jer-en-mu-

jer $=14$

di-cen-queen-los-so-la-res-de-mi-gen-teme-di-do $=14$

es-ta-ba-to-doa-que-Ilo-que-se-de-bí-aha-

cer $=14$

di-cen-que-si-len-cio-sas-las-mu-je-res-

han-si-do $=14$

de-mi-ca-sa-ma-ter-na (...) ah-bien-pudie-ra-ser $=14$

a-ve-ces-en-mi-ma-drea-pun-ta-ron-an-tojos $=13$

de-li-be-rar-se-pe-ro-se-le-su-bió-a-los-ojos $=15$

u-nahon-daa-mar-gu-ra-yen-la-som-braIlo-ró = 13

y-to-doe-so-mor-dien-te-ven-ci-do-mu-ti-

la-do $=14$

to-doe-so-que-seha-lla-baen-su-al-maen-

ce-rra-do $=13$

pien-so-que-sin-que-rer-lo-lohe-li-ber-tado-yo $=13$

Este poema foi escrito em dois quartetos e dois tercetos, ou seja, é um soneto. Os versos são irregulares, não obedecendo a uma metrificação constante. Possui rimas finais alternadas na primeira $e$ segunda estrofe e entrelaçadas na terceira e quarta estrofe.

Ao realizarmos uma primeira leitura, as rimas finais ficam evidentes e vão produzindo sentido importantes, por isso começamos analisando-as. $\mathrm{Na}$ rima entre sentido-reprimido-medido-sido, percebemos a repressão que as mulheres sofriam pela sociedade da época. Essas rimas também se relacionam com mutilado-encerrado, enfatizando a questão anterior do aprisionamento social das mulheres.

\footnotetext{
${ }^{2}$ Entende-se por grupos sintáticos os acentos que ocorrem em torno dos grupos de adjetivos, advérbios e verbos.
} 
Observando a rima final entre ser-mujer-hacerser-querer, a mulher, peça fundamental nos poemas escolhidos, é evidenciada, e notamos que a vontade da voz poética é de fazer e de ser alguém que foge aos padrões da época. Essas rimas sugerem essa busca da mulher em ser e fazer o que quiser.

Podemos perceber nas rimas internas e externas uma ordem de lutas e derrotas até alcançar a liberdade, sentido-vedado-reprimido-medido-sidovencido-mutilado-encerrado-libertado. A voz poética descreve como as mulheres foram sentindo $e$ reprimindo os seus desejos até conseguirem libertar-se. Percebemos que a vontade de gerar mudanças sociais era maior, e assim os movimentos de luta da voz poética a levaram a liberar-se das imposições da sociedade. Outra rima que também mostra essa relação de luta e sofrimento da voz poética é lloró-yo.

Ao observamos os ecos prosódicos do poema, percebemos as relações de sentido que produzem a significância do texto. Por meio dos ecos prosódicos, as palavras familia-mujer-materna-madre-amargura-alma relacionam-se dentro do poema, sugerindo que mulheres eram ensinadas por suas famílias a seguirem os padrões sociais da época. Percebemos ao longo do poema que as mulheres passavam seus ensinamos dentro da família, de mulher para mulher, elas deviam reprimir os sentimentos, calar os seus desejos. De gerações em gerações, eram transpassadas as instruções do que se debia hacer, porém nota-se que a voz poética enfatiza $A h$, bien pudiera ser, ou seja, mesmo ela sendo ensinada pelas mulheres da família a ser e se comportar dentro do ideal de mulher para a sociedade da época, ela não conseguiu sê-lo.

Quando nos debruçamos sobre os ecos prosódicos, é possível criar relações outras entre as palavras, bem como trazer novas significâncias ao poema. Os valores de como as mulheres deviam ser e se portar são sugeridos nos ecos entre: pudierasentido-vedado-rempimido-medido-vencido-mutiladoencerrado-libertado. Esses ecos vão evidenciando como as mulheres deviam se comportar, medir as palavras, esconder opiniões, também é possível compreender como essas restrições provocavam sofrimento. $O$ desejo por ser livre encontrava-se encerrado nas mulheres, a voz poética consegue libertá-lo. Ao considerarmos os ecos prosódicos entre ser-verso-solares-silenciosas-libertarse-sombra, percebemos novamente essa referência a como as mulheres deviam ser silenciosas e esconder os sentimentos nas sombras. Destacamos, ainda, o eco prosódico produzido entre as palavras com a letra "s" ser-sentido-solares-silenciosas-sido-sombra, nessas relações nota-se a referência às mulheres e ao movimento de ser, sentir e sair das sombras para serem livres.

Os poemas escolhidos para análise constroem uma voz poética que os perpassa e evidencia a força e a vontade de libertação da prisão social às quais as mulheres eram submetidas. No poema Bien pudiera ser percebemos que a voz poética anseia por ser livre, assim como no poema Van pasando mujeres, que analisaremos posteriormente. Essa busca, essa luta, esse desejo por liberdade para as mulheres permeia diversos poemas de Alfonsina Storni.

Feitas essas análises é possível voltar ao título do poema Bien pudiera ser e compreendê-lo melhor. Os ecos, as rimas, as relações produzidas pelo ritmo do poema estabelecem um valor, dentro do texto, relacionado ao ser mulher e como elas deveriam ser, comportar-se na sociedade da época. Percebemos também como a voz poética não conseguiu encaixar-se e libertou-se das amarras sociais. Enfatizamos que 0 valor que é construído pela luta das mulheres neste poema é único deste sistema de discurso, as rimas, os ecos produzem esse valor que perpassa todo o texto por meio do ritmo.

O segundo poema apresentado neste artigo é Van pasando mujeres, publicado no livro Languidez em 1920.

\footnotetext{
Cada día que pasa, más dueña de mí misma, sobre mí misma cierro mi morada interior; En medio de los seres la soledad me abisma.

Ya ni domino esclavos, ni tolero señor.

Ahora van pasando mujeres a mi lado cuyos ojos trascienden la divina ilusión. El fácil paso llevan de un cuerpo aligerado: se ve que poco o nada les pesa el corazón.
} 
Algunas tienen ojos azules e inocentes; Van soñando embriagadas, los pasos al azar;

La claridad del cielo se aposenta en sus frentes

y como son muy finas se les oye soñar.

Sonrío a su belleza, tiemblo por sus ensueños;

El fino tul de su alma, ¿quién lo recogerá? Son pequeñas criaturas, mañana tendrán dueños,

y ella pedirá flores..., y él no comprenderá.

Les llevo una ventaja que place a mi conciencia:

los sueños que ellas tejen no los supe tejer, y en manos ignorantes no perdí mi inocencia.

Como nunca la tuve, no la pude perder.

Nací yo sin blancura; pequeña todavía el pequeño cerebro se puso a combinar; Cuenta mi pobre madre que, como comprendía,

yo aprendí muy temprano la ciencia de llorar.

Y el llanto fue la llama que secó mi blancura en las raíces mismas del árbol sin brotar, y el alma está candente de aquella quemadura.

¡Hierro al rojo mi vida! ¿Cómo pude durar?

Alma mía, la sola; tu limpieza, escondida con orgullo sombrío, nadie la arrullará;

Si en música divina fuera el alma dormida, el alma, comprendiendo, no despertara ya.

Tengo sueño mujeres, tengo un sueño profundo.

Oh humanos, en puntillas el paso deslizad; mi corazón susurra: me haga silencio el mundo,

y mi alma musita fatigada: ¡callad!...

A seguir, apresentamos a escansão do poema usando a métrica espanhola, grafando as sílabas fortes a fim de ouvir os acentos sintáticos do poema.

Ca-da-dí-a-que-pa-sa-más-due-ña-de-mímis-ma $=14$

So-bre-mí-mis-ma-cie-rro-mi-mo-ra-dainte-rior $=14$

En-me-dio-de-los-se-res-la-so-le-dad-

mea-bis-ma $=14$

Ya-ni-do-mi-noes-cla-vos-ni-to-le-ro-se-

ñor $=14$
Aho-ra-van-pa-san-do-mu-je-res-a-mi-lado $=13$

Cu-yos-o-jos-tras-cien-den-la-di-vi-nai-lusión $=14$

El-fá-cil-pa-so-lle-van-deun-cuer-poa-lige-ra-do $=14$

Se-ve-que-po-coo-na-da-les-pe-sael-cora-zón $=14$

Al-gu-nas-tie-nen-o-jos-a-zu-les-ei-nocen-tes $=14$

Van-so-ñan-doem-bria-ga-das-los-pa-sosal-a-zar $=14$

La-cla-ri-dad-del-cie-lo-sea-po-sen-taen-

sus-fren-tes $=14$

y-co-mo-son-muy-fi-nas-se-les-o-ye-so-

$\tilde{\text { ñar }}=14$

Son-rí-oa-su-be-lle-za-tiem-blo-por-susen-sue-ños $=14$

El-fi-no-tul-de-sual-ma-quién-lo-re-co-gerá $=14$

Son-pe-que-ñas-cria-tu-ras-ma-ña-na-tendrán-due-ños $=14$

Ye-lla-pe-di-rá-flo-res-yél-no-com-pren-derá $=14$

Les-Ile-vou-na-ven-ta-ja-que-pla-cea-micon-cien-cia $=14$

Los-sue-ños-que-ellas-te-jen-no-los-supe-te-jer $=14$

Yen-ma-nos-ig-no-ran-tes-no-per-dí-miino-cen-cia $=14$

Co-mo-nun-ca-la-tu-ve-no-la-pu-de-perder $=14$

Na-cí-yo-sin-blan-cu-ra-pe-que-ña-to-daví-a $=14$

El-pe-que-ño-ce-re-bro-se-pu-soa-com-binar $=14$

Cuen-ta-mi-po-bre-ma-dre-que-co-mocom-pren-dí-a $=14$

Yoa-pren-dí-muy-tem-pra-no-la-cien-ciade-llo-rar $=14$

Yel-llan-to-fue-la-lla-ma-que-se-có-miblan-cu-ra $=14$

En-las-ra-í-ces-mis-mas-del-ár-bol-sinbro-tar $=14$

Yel-al-maes-tá-can-den-te-dea-que-llaque-ma-du-ra $=14$

Hie-rroal-ro-jo-mi-vi-da-có-mo-pu-de-durar $=14$

Al-ma-mí-a-la-so-la-tu-lim-pie-zaes-condi-da $=14$

Con-or-gu-llo-som-brí-o-na-die-laa-rru-llará $=14$

Sien-mú-si-ca-di-vi-na-fue-rael-al-ma-dormi-da $=14$ 
El-al-ma-com-pren-dien-do-no-des-per-tara-ya $=14$

Ten-go-sue-ño-mu-je-res-ten-goun-sueño-pro-fun-do $=14$

Ohhu-ma-nos-en-pun-ti-llas-el-pa-so-des-

li-zad $=14$

mi-co-ra-zón-su-su-rra-meha-ga-si-len-

cio-el-mun-do $=15$

y-mial-ma-mu-si-ta-fa-ti-ga-da-ca-llad = 13

Este poema foi escrito em nove estrofes de quatro versos cada uma. Na maioria dos versos há uma metrificação constante. Possui rimas finais alternadas. Iniciamos observando essas rimas e percebemos que a voz poética encontra-se em luta, dueña de mi misma, para conseguir sentir-se dona de si e libertar-se das imposições sociais; la soledad me abisma, mas ela sente-se sozinha nessa luta e isso a deixa abismada. Na rima entre interior-señor há a sugestão da imposição masculina dentro do lar. $\mathrm{Na}$ rima entre ilusión-corazón percebemos a voz poética diferenciando-se das outras mulheres, uma vez que essas mulheres têm o coração iludido, são inocentes, aceitam as imposições sociais com tranquilidade. Essas mulheres possuem ensueños-dueños, diferentemente da voz poética.

As mulheres que passam pela voz poética possuem sonhos, são inocentes, criadas para serem submissas às imposições sociais e aos homens. Por sua vez, a voz poética não soube tejer-perder esses sentimentos, ela não tinha os mesmos sonhos inocentes das outras mulheres, portanto, não irá perdê-los. Na relação entre blancura-quemadura percebemos a brancura como a inocência e a queimadura como a inocência destruída. Notamos essa sugestão da perda da inocência na rima entre brotar-durar. A voz poética tem um sueño profundo silencio el mundo, percebemos nessa relação que a voz poética luta, tem o sonho de libertação das imposições sociais às que as mulheres eram submetidas. Um sonho de liberdade, de que as mulheres percebam e lutem também e que o mundo fique em silêncio para aqueles sonhos submissos.

Na primeira leitura observamos as relações entre as rimas finais. Logo, conforme propõe a poética, vamos além dos sentidos sugeridos pelas rimas finais e buscamos atentar para as relações que se estabelecem por meio dos ecos prosódicos. Esses ecos produzem sentidos outros que não ficam evidentes em uma primeira leitura.

Iniciamos considerando os ecos entre díadueña-soledad-domino-pasando-trascienden-

calridad-madre-candente-vida-despertara,

percebemos características da voz poética, de suas lutas e das outras mulheres. Notamos nesses ecos que a voz poética lutou para ser dona de si mesma e libertar-se do domínio dos homens, também percebemos as marcas deixadas por essa luta, a solidão. O ritmo do texto é percebido, também, pelos ecos prosódicos que produzem sentidos e significam no poema.

No eco entre pasando-cuerpo-pesaaposenta-pequeña-comprendera-place-pobre-

profundo-puntillas percebemos a sugestão do movimento da voz poética, a luta desde pequena por liberdade. A voz nota que as outras mulheres têm sonhos profundos, um caminhar leve, mas ela não as compreende. Outro eco que destacamos em nossa análise é entre mí-domino-mujeres-alma-madremúsica-dormida-humanos-mundo-musita, a voz poética inicia uma luta por liberdade, ela consegue dominar as suas vontades, a sua luta é levada para a sua mãe, para as outras mulheres, para o mundo como uma música que desperta os adormecidos.

No poema, as mulheres que se encaixam nos padrões sociais da época são caracterizas pelos ecos seres-pasando-transcienden-ilusión-corazóninocentes-azar-cielo-ensueños. Nesses ecos percebemos a sugestão de que as mulheres não notam as imposições sociais às que são subjugadas, pois elas são criadas dentro dessa ilusão. Relacionamos esses ecos com os ecos entre cierroconciencia-inocencia-nací-susurra-musita que vão sugerindo caracterizações da voz poética. Percebemos que a voz é consciente das imposições sociais e não possui a inocência que as mulheres, em geral, têm. A voz poética aprendeu muito nova a se impor de forma sussurrante e imponente, sua mente é livre das amarras sociais. 
Outra relação de sugestão por meio de ecos prosódicos que percebemos no poema é entre morada-aligerado-ignorantes-llorar-arrullará. A voz poética observa o lugar onde situa-se e compreende que as mulheres ao seu redor são ignorantes em relação à situação de submissão em que se encontram. A voz poética chora pela violência e pela submissão a que as mulheres são subjugadas pela sociedade. No eco prosódico entre señor-soñandosoñar percebemos que os homens detinham o poder, eram senhores de suas mulheres, elas apenas obedeciam, sem sequer poder sonhar.

Diversos poemas de Storni relatam essa situação de imposições às que as mulheres eram subjugadas pelos maridos e pela sociedade. A poeta, por meio de sua escrita, busca evidenciar essa situação, denunciar as submissões, exaltar a busca pela libertação e pelos direitos das mulheres. No poema acima, percebemos um eco prosódico entre esclavos-cuerpo, nessa relação notamos que a voz poética denuncia que os corpos das mulheres eram escravos dos homens e da sociedade.

Após ter observando todas essas relações produzidas dentro do poema, voltamos ao título Van pasando mujeres e compreendemos esse passar das mulheres. Há um movimento de luta, de busca pela liberdade, anseio por mudanças e conquistas de direitos para as mulheres. A voz poética tem esses sonhos de libertação feminina, e isso vai sendo passado para as outras mulheres que vão percebendo essa necessidade de lutar. No eco entre tiemblo-criaturas-ventaja-tejen-brotar, a voz poética alcança as outras mulheres com os seus sonhos e as ensina a deixar de 'tricotar' e de aceitar tudo o que sociedade impunha.

A voz poética consegue fazer brotar nas outras mulheres, que vão passando por ela, esse desejo de luta e busca por liberdade. Todos essas relações observadas e colocadas em discussão neste trabalho sugerem um valor que é único desse poema em relação à luta das mulheres por liberdade, à força da voz poética para mudar a sociedade.

\section{Uma proposta poética de tradução dos poemas de Storni}

A seguir apresentamos nossa proposta de tradução para o poema Bien pudiera ser de Alfonsina Storni. Em nossa versão o poema o título do poema ficou Pode ser.

Pode ser que tudo o que em versos tenho sentido

não seja mais que aquilo que nunca poderia ser,

não seja mais que algo vedado e reprimido de família em família, de mulher para mulher.

Dizem que nos ancestrais da minha gente, medido

estava tudo aquilo que se devia fazer...

Dizem que silenciosas as mulheres têm sido

da minha casa materna... É, pode ser...

Às vezes em minha mãe brotaram sonhos de libertar-se, mas, surgiu em seus olhos uma profunda amargura, e na sombra gemeu.

E tudo isso mordente, destruído, mutilado, tudo isso que em sua alma se encontrava encerrado,

penso que sem querer o tenha libertado eu.

A seguir, apresentamos a escansão do poema usando a métrica brasileira, grafando as sílabas fortes a fim de ouvir os acentos sintáticos do poema.

Po-de-ser-que-tu-doo-que-em-ver-sos-tenho-sen-ti-do $=15$

não-se-ja-mais-que-a-qui-lo-que-nun-ca-

po-de-ri-a-ser $=16$

não-se-ja-mais-que-al-go-ve-da-doe-re-

pri-mi-do $=13$

de-fa-mí-lia-em-fa-mí-lia-de-mu-lher-pa-ra-

mu-lher $=15$

di-zem-que-nos-an-ces-trais-da-mi-nha-

gen-te-me-di-do $=14$

es-ta-va-tu-doa-qui-lo-que-se-de-vi-a-fa-

zer $=14$

di-zem-que-si-len-ci-o-sas-as-mu-Ihe-restêm-si-do $=14$ 
da-mi-nha-ca-sa-ma-ter-na (...) é-po-deser $=12$

às-ve-zes-em-mi-nha-mãe-bro-ta-ram-sonhos $=13$ de-li-ber-tar-se-mas-sur-gi-uem-seus-oIhos $=11$ u-ma-pro-fun-daa-mar-gu-rae-na-sombra-ge-meu $=12$

e-tu-doi-sso-mor-den-te-des-tru-í-do-mu-tila-do $=14$

tu-doi-sso-que-em-su-aal-ma-seen-con-

tra-va-en-ce-rra-do $=15$

pen-so-que-sem-que-rer-a-te-nha-li-ber-

ta-doeu $=15$

Na versão original, em espanhol, o poema foi escrito por Storni em versos sem uma metrificação regular. Assim, a nossa proposta tradutória também não seguiu uma metrificação regular.

Nesse poema há rimas internas e finais, ao buscar recriá-las, na maioria, não enfrentamos dificuldades. Foi necessária maior dedicação aos ecos prosódicos entre ser, sentido, solares, silenciosas, sido e sombras, pois foi preciso buscar uma palavra que recriasse a relação de sentido do poema e também o eco no texto. Solares em nossa proposta foi traduzido por ancestrais, pensando a relação estabelecida dentro do discurso do poema, já que, em nossa compreensão, solares faz referência à descendência da voz poética.

Nossa proposta tradutória também procurou recriar os ecos prosódicos entre famíliamulher-materna-mãe-amargura-mordente-alma,

pois nessas relações há a sugestão de como as mulheres eram ensinadas por suas mães a reprimirem os sentimentos, e a voz poética logra quebrar com esse ciclo e liberta-se das imposições sociais às que as mulheres eram subjugadas. Buscamos recriar também os ecos entre pudessesentido-vedado-reprimido-medido-destruidomutilado-encerrado-libertado, pois neles percebemos a sugestão de como as mulheres deveriam reprimir, medir suas palavras, encerrar os sentimentos, e, novamente, a voz do poema quebra com isso e consegue libertar-se desse sofrimento. Outro eco que foi recriado é entre ser-versoancestrais-silenciosas-sombra-encerrado-penso, também há a sugestão desse silenciamento das mulheres.

Quando voltamos ao título do poema, Pode ser, notamos o valor estabelecido as mulheres nesse sistema de discurso. Há uma voz poética que foge aos padrões, quebra com as imposições sociais, compreendemos o verso quem me dera ser como uma crítica, pois ela não é e tampouco quer ser como as outras mulheres. Todas as relações produzidas dentro do poema pelos ecos prosódicos, as rimas internas e finais, constroem um valor único em relação à crítica da voz poética, esses valores perpassam todo o poema.

A segunda proposta tradutória apresentada neste artigo é a do poema Van pasando mujeres. Em nossa versão o título ficou Vão passando mulheres.

Cada dia que passa, mais dona de mim mesma,

sobre mim fecho minha morada interior; no meio dos seres a solidão me abisma. Já não domino escravos nem tolero senhor.

Agora vão passando mulheres ao meu lado os seus olhos transcendem a divina ilusão. O fácil caminhar levam de um corpo apressado:

vê-se que pouco ou nada pesa o coração.

Algumas delas têm olhos azuis e inocentes; vão sonhando embriagadas, andando ao azar;

a claridade do céu repousa em suas mentes

e como são delicadas as ouço sonhar.

Sorrio pela beleza, tremo por seus sonhos; o fino véu de sua alma, quem o guardará? São pequenas criaturas, logo terão donos, e ela pedirá flores... e ele não entenderá.

Tenho uma vantagem que alegra minha consciência:

os sonhos que elas tecem eu não soube tecer,

e em ignorantes não perdi minha inocência. Como jamais a tive, não a pude perder.

Eu nasci sem a brancura; pequena ainda o pequeno cérebro começara a pensar; 
conta minha pobre mãe que, como entendia,

aprendi muito cedo a ciência de chorar.

Foi o choro a chama que secou minha brancura

e nas raízes mesmas da árvore sem brotar, e a alma está ardente daquela queimadura. Ferro em brasas minha vida! Como pude durar?

Minha alma, única; tua limpeza, escondida com orgulho sombrio, ninguém a sossegara;

Se em música divina fora alma adormecida, a alma, compreendendo, não despertara já.

Tenho sonhos mulheres, tenho um sonho profundo.

Oh humanos, delicadamente o passo deslizai;

Meu coração sussurra: faça silêncio, mundo,

e minha alma murmura fatigada: calai!...

A seguir, mostramos a escansão feita, seguindo a métrica brasileira, grafando as sílabas fortes a fim de ouvir os acentos sintáticos do poema.

Ca-da-dia-que-pa-ssa-mais-do-na-demim-mes-ma $=12$

so-bre-mim-fe-cho-mi-nha-mo-ra-dain-terior $=12$

no-mei-o-dos-se-res-a-so-li-dão-mea-bis-

$\mathrm{ma}=12$

Já-não-do-mi-noes-cra-vos-nem-to-le-rose-nhor $=13$

A-go-ra-vão-pa-ssan-do-mu-lhe-res-aomeu-la-do $=13$

os-seus-o-Ihos-trans-cen-dem-a-di-vi-nailu-são $=13$

O-fá-cil-ca-mi-nhar-le-vam-deum-cor-poapre-ssa-do $=13$

vê-se-que-pou-co-ou-na-da-pe-sao-co-ração $=13$

Al-gu-mas-de-las-têm-o-lhos-a-zuis-ei-nocen-tes $=13$

vão-so-nhan-doem-bri-a-ga-das-na-dan-

doa-oa-zar $=13$

a-cla-ri-da-de-do-céu-re-pou-saem-su-asmen-tes $=13$

e-co-mo-são-de-li-ca-das-as-ou-ço-so-

nhar $=13$
So-rri-o-pe-la-be-le-za-tre-mo-por-seusso-nhos = 13

o-fi-no-véu-de-su-aal-ma-quem-o-guarda-rá $=13$

São-pe-que-nas-cri-a-tu-ras-lo-go-te-rãodo-nos $=13$

ee-la-pe-di-rá-flo-res-ee-le-não-en-ten-derá $=14$

Te-nhou-ma-van-ta-gem-quea-le-gra-minha-cons-ci-ên-cia $=14$

os-so-nhos-quee-las-te-cem-eu-não-soube-te-cer $=13$

eem-mãos-ig-no-ran-tes-não-per-di-minhai-no-cên-cia = 13

Co-mo-ja-mais-a-ti-ve-não-a-pu-de-perder $=13$

Eu-nas-ci-sem-a-bran-cu-ra-pe-que-naain-da $=12$

o-pe-que-no-cé-re-bro-co-me-ça-raa-pensar $=13$

con-ta-mi-nha-po-bre-mãe-que-co-moenten-di-a $=12$

a-pren-di-mui-to-ce-doa-ci-ên-cia-de-cho$\operatorname{rar}=13$

Foi-o-cho-roa-cha-ma-que-se-cou-minha-bran-cu-ra = 13 e-nas-ra-í-zes-mes-mas-daar-vo-re-sembro-tar $=13$

ea-al-maes-tá-ar-den-te-da-que-la-queima-du-ra $=13$

Fe-rroem-bra-sas-mi-nha-vi-da-co-mo-pude-du-rar $=14$

mi-nhaal-ma-ú-ni-ca-tu-a-lim-pe-zaes-condi-da $=13$

com-or-gu-lho-som-bri-o-nin-guém-a-sosse-ga-ra $=13$

Seem-mú-si-ca-di-vi-na-fo-raal-maa-dorme-ci-da $=13$

Aal-ma-com-pre-en-den-do-não-des-perta-ra-já $=13$

Te-nho-so-nhos-mu-lhe-res-te-nhoum-sonho-pro-fun-do $=13$

Oh(...)hu-ma-nos-le-ve-men-teo-pa-ssodes-li-zai $=13$

Meu-co-ra-ção-su-ssu-rra-fa-ça-si-lên-ciomun-do = 13

e-mi-nhaal-ma-mur-mu-ra-fa-ti-ga-da-calai $=13$

O poema em espanhol foi escrito em versos sem uma metrificação regular, uma marca da escrita poética de Storni. Encontramos algumas dificuldades em recriar algumas das rimas finais do poema. São elas misma-abisma, todavía-comprendía, arrullará-ya, 
em nossa proposta ficaram mesma-abisma, aindaentendia, sossegara-já. Essas escolhas não recriam a rima, porém, produzem o sentido do movimento de luta da voz poética.

Enfrentamos, também, dificuldade no verso Hierro al rojo mi vida, essa frase sugere um grito de luta da voz poética. Uma tradução que considerasse apenas o sentido proporia Ferro ao vermelho minha vida, porém perderíamos o efeito do original. Outras possibilidades seriam Ferro ardente minha vida, Ferro ao rubro minha vida, Ferro em brasas minha vida. Levando em consideração o proposto pela poética de traduzir em relação à indissociabilidade a forma e o sentido, o som e sentido, nossa escolha tradutória foi Ferro em brasas minha vida, pois compreendemos que assim recria-se o grito de luta da voz poética e as relações de valores que são produzidas ao longo do poema.

Quando a voz poética diz: Oh humanos, en puntillas el paso deslizad também foi preciso observar e escolher uma tradução que levasse em consideração o sistema de discurso do poema. Nessa frase entendemos que a voz do poema apela para que as pessoas caminhem de forma mais leve. Algumas das opções tradutórias, se e considerasse apenas o sentido, eram: Oh humanos, em pontinhas o passo deslizai, Oh humanos, levemente o passo deslizai, Oh, humanos delicadamente o passo deslizai. Buscando considerar a relação indissociável entre a forma e o sentido, o som e o sentido, nossa escolha foi: Oh humanos, levemente o passo deslizai. Entendemos que assim recriamos o apelo da voz poética e também as relações que vão produzindo-se ao longo do poema.

Nossa proposta tradutória também buscou recriar os ecos prosódicos entre dia-dona-solidãoclaridade-domino-passando-transcendem-ardentevida-despertara, percebemos que nesses ecos há a sugestão da luta da voz poética para ser sua própria dona e se libertar das imposições dos homens. Recriamos 0 eco entre mim-morada-domínomulheres-alma-mãe-música-adormecida-humanosmundo-murmura, observamos nessas relações a busca da voz poética para sair do domínio dos homens, a voz poética desperta as mulheres adormecidas e as incentiva a lutarem por liberdade.

Outros ecos prosódicos considerados em nossa tradução foram seres-passando-transcendemilusão-coração-inocentes-azar-céu-sonhos, percebemos a sugestão da passagem das mulheres pelas imposições sociais, a inocência delas por serem criadas na ilusão de que devem obedecer aos homens. Nos ecos entre consciência-inocêncianasci-sussurra, notamos a sugestão de uma consciência da voz poética perante as imposições sociais; ela não é inocente como as outras mulheres. Nos ecos entre passando-corpo-pesa-repousapequena-pobre-profundo, observamos a sugestão de um movimento da voz poética, ela luta, carrega o peso de ser diferente, foge aos padrões sociais da época. Nos ecos entre senhor-sonhando-sonhos, percebemos a sugestão dos homens impondo sonhos as mulheres.

Outra relação importante no poema é entre escravos-corpo, a voz poética luta por liberdade, não aceita as imposições sociais as que as mulheres eram subjugadas. Nesse eco notamos a sugestão de que os corpos das mulheres eram escravos dos maridos. No eco entre treme-criaturas-vantagem-tecembrotar, percebemos a voz poética com medo, mas ela busca alcançar as outras mulheres para incentivá-las a lutar, fazer brotar o sentimento de busca pela liberdade feminina.

Após feitas as análises e as relações dentro do poema, voltamos ao título, Vão passando mulheres, e percebemos esse movimento de luta e de busca por liberdade da voz poética. Todas as relações produzidas no poema sugerem um valor único desse texto à luta das mulheres. Nosso processo tradutório, buscou recriar a significância do poema em espanhol, considerando os acentos, as rimas finais e internas, os ecos prosódicos, sempre procurando traduzir o ritmo do poema.

\section{Considerações finais}

Buscamos ao longo do trabalho discutir e refletir sobre a tradução a partir da relação entre a 
forma e o sentido, o som e o sentido, ou seja, a partir do ritmo na tradução. Para esse fim, a poética do traduzir, proposta por Meschonnic, mostrou-se pertinente.

O nosso projeto tradutório prioriza o discurso com base na teoria meschonniquiana. Meschonnic aborda em sua poética a importância de se observar os ecos prosódicos, as rimas, o ritmo apoiando-nos nas relações produzidas em todo o texto, e não apenas nas rimas finais, por exemplo. A poética do traduzir propõe que não devemos dissociar a forma e o sentido, pois se o fizermos, perde-se o efeito do texto, a significância do texto, que é o mais importante a ser recriado.

Meschonnic ([1999] 2010), em seu fazer teórico, propõe a tradução de discursos, que produzem efeito, que possuem ritmo. Com isso, a poética meschonniquiana diferencia-se de outras teorias de tradução. Distancia-se principalmente por considerar o discurso como um contínuo, o ritmo do texto é que será traduzido. Para o teórico, as traduções não são apenas a passagem de uma língua para outra, as traduções envolvem questões de linguagem, de cultura, de sociedade. Assim, não traduzimos apenas palavras, traduzimos discursos carregados de significância.

O ritmo proposto por Meschonnic ([1999] 2010) constrói-se a partir de discursos, considerando relações entre os textos. São essas relações, esse ritmo, que buscamos observar em nossas traduções. Atentamos para as relações sintagmáticas e paradigmáticas produzidas no sistema do discurso. Observamos as rimas, os acentos sintáticos, os ecos prosódicos, o efeito que o texto original buscou construir e tentamos levar esse ritmo do espanhol para o português.

Feitas as leituras, análises, a busca de poemas, críticas sobre a autora, é possível dizer que os poemas apresentam uma voz à frente de seu tempo. Tais poemas buscaram, colocar em discussão questões relacionadas ao ser mulher no século XX. A leitura e tradução dos textos dessa poeta do século $X X$ é fundamental e necessária, pois a força, o grito de liberdade se faz necessário, ainda, no século XXI.
Nosso intuito foi de relacionar as vozes dos textos, os ecos prosódicos, as relações sintáticas, buscando novas correspondências. As relações internas, estabelecidas por meio do ritmo, evidenciam a busca por libertação das amarras sociais. As relações produzidas pelos ecos prosódicos vão gerando valores, uma palavra vai construindo o sentido das outras naquele texto. Foi possível depreender os valores do ser mulher no século $X X$, das restrições impostas às mulheres. No poema "Bien pudiera ser" a voz poética anseia por ser livre, tal como no poema "Van pasando mujeres" nota-se o movimento das mulheres, de luta e busca por liberdade.

Ao longo do trabalho, procuramos observar e relacionar a teoria e a prática, buscando sempre um enriquecimento teórico. Por ser o discurso um sistema de infinitas possiblidades, sabemos que as análises feitas nesse trabalho não esgotaram os olhares e análises que ainda podem ser feitas sobre os poemas.

\section{Referências}

BENVENISTE, É. Problemas de Linguística Geral I. Tradução de Maria da Gloria Novak, Maria Luisa Neri. 5ª ed. Campinas: Pontes Editora, [1966] 2005.

. Problemas de Linguística Geral II. Tradução de Eduardo Guimaraes, et al. $2^{\mathrm{a}}$ ed. Campinas: Pontes Editora, [1974] 2006.

MESCHONNIC, H. Crisis del signo: política del ritmo y teoría del lenguaje. Tradução de Guillermo PiñaContreras. Santo Domingo: Comisión permanente de la feria del libro, 2000.

La poesía como critica del sentido. Tradução de Hugo Savino. Buenos Aires: Mármol-Izquierdo editores, 2007.

Poética do traduzir. Tradução de Jerusa Pires Ferreira, Suely Fenercih. São Paulo: Pespectiva, [1999] 2010.

NEUMANN, D. Em busca de uma Poética da Voz. 2016. $175 \mathrm{f}$. Tese (doutorado em

Letras) - Instituto de Letras, Universidade Federal do Rio Grande do Sul, Porto Alegre. 2016. Disponível em: <https://lume.ufrgs.br/handle/10183/140254>. Acesso em: 24 jan. 2020

SAUSSURE, F. de; Curso de Linguística Geral. Tradução de Antônio Chelini, José Paulo Paes, Izidoro Blikstein. 28aa ed. São Paulo: Cultrix, [1916] 2012.

STORNI, A. El Dulce Daño. Buenos Aires: Sociedad cooperativa editorial limitada, 1918. Disponível em: <https://upload.wikimedia.org/wikipedia/commons/b/b4/El 
_Dulce_Da\%C3\%B10_Alfonsina_Storni.pdf>. Acesso

èm: 20 jan. 2020.

Languidez: versos. Buenos Aires: Sociedad cooperativa editorial limitada, 1920. Disponível em: <https://upload.wikimedia.org/wikipedia/commons/e/e7/L anguidez_Alfonsina_Storni.pdf $>$. Acesso em: 20 jan. 2020 .

SAVIA VIDALES, Antonella Romina. Movimento de luta das mulheres nos poemas de Storni: uma proposta de tradução. Signo, Santa Cruz do Sul, v. 46, n. 87, sep. 2021. ISSN 1982-2014. Disponível em: <https://online.unisc.br/seer/index.php/signo/article/view/16533>. doi:https://doi.org/10.17058/signo.v46i87.16533. 